XIN HONG, B.Eng. ${ }^{1}$

E-mail: hongxin@bjtu.edu.cn

LINGYUN MENG, Ph.D. ${ }^{1}$

(Corresponding author)

E-mail: lymeng@bjtu.edu.cn

JIAN AN, Ph.D. ${ }^{2}$

E-mail: Marlin_tree@163.com

${ }^{1}$ School of Traffic and Transportation

Beijing Jiaotong University

Beijing, 100044, China

${ }^{2}$ Shenzhen Urban Transport Planning Center CO., LTD,

Shenzhen, 518026, China
Traffic in the Cities Original Scientific Paper Submitted: 10 Feb. 2018 Accepted: 19 Feb. 2020

\title{
QUANTIFYING TRAVEL PHYSICAL ENERGY EXPENDITURE FOR URBAN TRAVELLERS - A CASE STUDY OF BEIJING
}

\begin{abstract}
Travel physical energy expenditure for travellers has impact on travel mode choice behaviour. However, quantitative study on travel physical energy expenditure is rare. In this paper, the concept of travel physical energy expenditure coefficient has been presented. A case study has been carried out of young travellers in Beijing to get the value of physical energy expenditure per unit time under three transport modes, walking, car and public transportation. A series of experiments have been designed and conducted, which consider influence factors including age, gender, travel mode, riding posture, luggage level and crowded level. By analysing the travel data of money, travel time and physical energy expenditure, we determined that the value of travel physical energy expenditure coefficient $\delta$ is $0.058 \mathrm{RMB} / \mathrm{KJ}$, which means that travellers can pay $0.058 \mathrm{RMB}$ to reduce $1 \mathrm{KJ}$ physical energy expenditure. Next, a travel mode choice model has been proposed using a multinomial logit model (MNL), considering economic cost, time cost and physical energy cost. Finally, the case study based on OD from Xizhimen to Tiantongyuan in Beijing was conducted. It is verified that it will be in better agreement with the actual travel behaviour when we take the physical energy expenditure for different types of travellers into account.
\end{abstract}

\section{KEY WORDS}

travellers' physical energy expenditure; travel behaviour; travel mode choice;

\section{INTRODUCTION}

It is important now to give priority to the development of public transportation in most cities all over the world, in order to mitigate urban traffic congestion and achieve urban traffic low-carbon, environmental protection, and sustainable development. However, as the living standard for people improves gradually, the sensitivity towards time and money has weakened, while the aspect of comfort has become a more important factor when people make a travel plan. People try to avoid the discomfort in daily travel by means of paying for a more comfortable travel plan.

Some studies at home and abroad pay attention to travellers' physiological and psychological aspects [1-6]. Due to the lack of methods for measuring the travellers' perceived comfort during travelling, there is little research on describing it objectively and quantitatively. Travel physical energy expenditure (TPEE) refers to the physical energy expenditure of travellers in one process of travelling, which quantitatively describes the comfort level of travelling from the perspective of energy metabolism. When physical energy expenditure reaches a certain level, travellers will have a feeling of discomfort, such as fatigue, boredom and so on, which works negatively when travellers make a plan for the next travel. Travellers will estimate the physical energy expenditure of each alternative travel plan according to their previous travel experience, and consider travel time and money together in advance. Ultimately, the travellers will choose an appropriate travel plan.

However, physical energy expenditure are the energy transformation processes within the human body, which are difficult to be measured. In addition, travellers with different physique have different perception for the same physical energy expenditure. Therefore, this paper puts forward the concept 


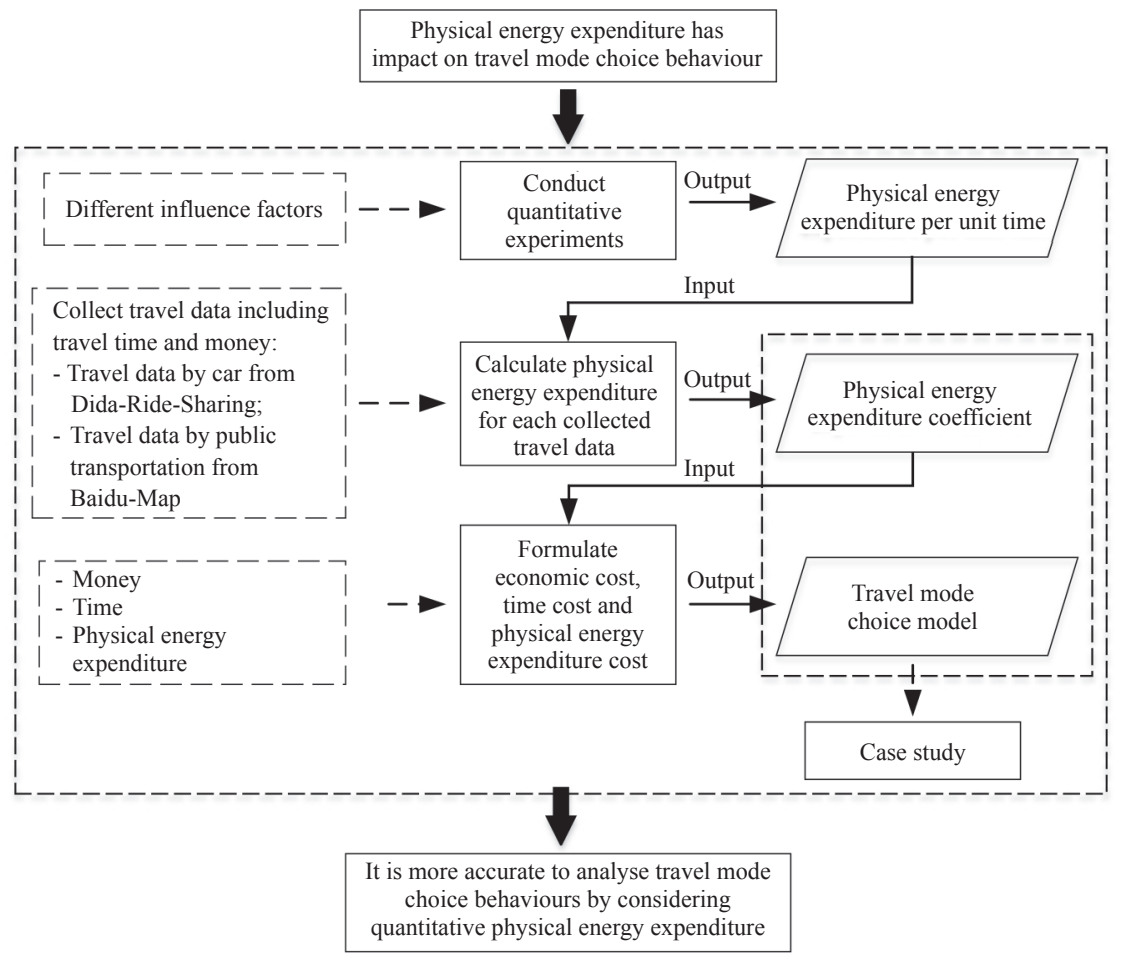

Figure 1 - Illustration of the technical route

of travel physical energy expenditure coefficient, transforming the physical energy expenditure into economic cost. And then, based on the traditional travel mode choice model considering money and travel time, the physical energy expenditure will be added into consideration by using a multinomial logit model (MNL). Based on the case study, we verify that the physical energy expenditure is a key factor for analysing people's travel behaviour.

The rest of the paper is organized as follows. Section 2 presents the quantitative experiments and results. Section 3 determines the value of travel physical energy coefficient. Section 4 proposes a transport mode choice model. In Section 5, a case study is conducted to verify the necessity of considering TPEE in travel behaviour. Section 6 gives the conclusions. The technical route of this paper is presented in Figure 1.

\section{QUANTITATIVE EXPERIMENTS AND RESULTS}

Body energy metabolism is divided into three types: basic metabolism, rest metabolism, and activity metabolism, which is a complex physiological process influenced by many factors. Basic metabolism and rest metabolism vary with gender and age; generally speaking, men above women, children above adults, and adults above the elderly [3].
Activity metabolism is closely related not only to individual characteristics, but also to the intensity of activities people are engaged in. This paper considers that the activity metabolism of travel behaviour is related to some individual characteristics like age, gender, and some activity characteristics like travel mode, riding posture, luggage level, crowded level. Figure 2 summarizes the influence factors of travel physical energy expenditure considered in this paper.

Guo [3] pointed out that the average basic metabolic rate of healthy people of the same gender over 20 years of age is almost the same. Travellers of this age group account for more than $98 \%$ of total urban rail transit passengers [9]. Therefore, in order to save the experimental cost, this paper chooses young people as the experiment sample. The experiment scenarios are designed using orthogonal experiment design method, comprehensively considering five factors including gender, travel mode, riding posture, luggage level and crowded level. Orthogonal experimental design method is an optimal method when there are many factors considered in experiments. Representative experiments will be selected according to the orthogonality from all experiments where every possible value for every factor is combined. And all the selected representative experiments are evenly distributed among all 


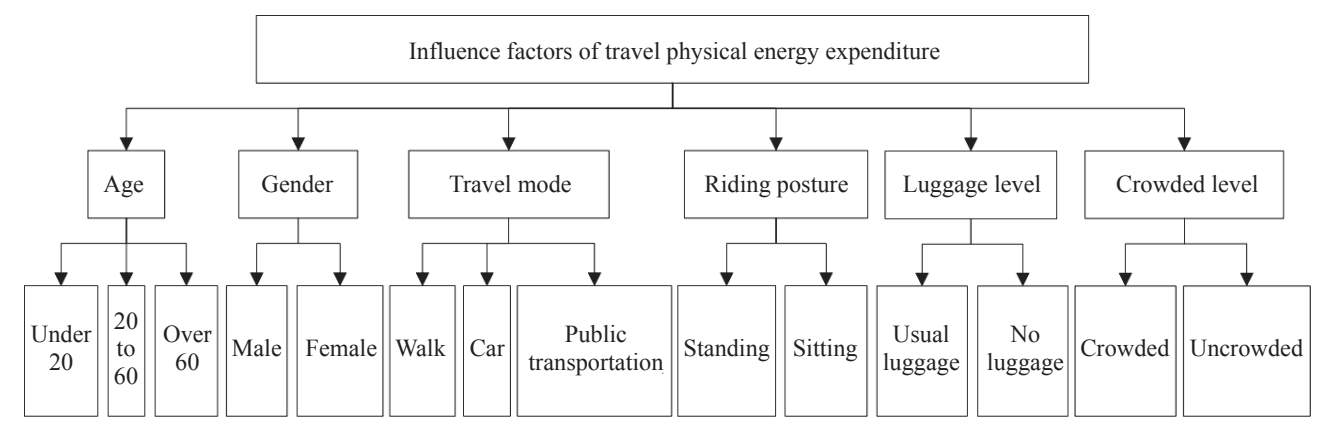

Figure 2 - Influence factors of travel physical energy expenditure

Notes: (1) Usual luggage refers to one laptop bag or one briefcase that commuters take every day.

(2) Crowded refers to the situation where it will be difficult if more people want to get on the bus or rail carriage. Uncrowded refers to the situation where it will be easy if anyone wants to get on the bus or rail carriage.

experiments and are mutually comparable. Conclusions can be obtained from relatively fewer number of experiments by orthogonal experiment design method, which is an efficient and economical method. The experimental scenarios are shown in Table 1. The environment of public transportation is complex resulting in physical energy expenditure influenced by many factors. Therefore, the experimental scenarios for public transportation are relatively complex, such as from the $5^{\text {th }}$ to the $20^{\text {th }}$ one in Table 1.
A typical OD in Beijing from Xizhimen to Qinghe was chosen as the experiment route. A total of 20 people were selected to be tested, and all of them (10 males, 10 females) had a normal BMI index (Body Mass Index). They were required to complete the corresponding experiment scenarios according to their own gender and record corresponding travel time and travel physical energy expenditure measured by the Polar cardio tachometer [7]. Finally, more than 200 pieces of experiment data were collected. The results of experiments are also shown in Table 1.

Table 1 - Experiment scenarios and results

\begin{tabular}{||c|c|c|c|c|c|c|c||}
\hline Scenario & Travel mode & Gender & $\begin{array}{c}\text { Luggage } \\
\text { level }\end{array}$ & $\begin{array}{c}\text { Riding } \\
\text { posture }\end{array}$ & $\begin{array}{c}\text { Crowded } \\
\text { level }\end{array}$ & $\begin{array}{c}\text { Range of TPEE } \\
{[\mathrm{KJ} / \mathrm{min}]}\end{array}$ & $\begin{array}{c}\text { Mean value of } \\
\text { TPEE [KJ/min] }\end{array}$ \\
\hline \hline 1 & Walk & Female & - & - & - & $10.05-15.62$ & 13.05 \\
\hline 2 & Walk & Male & - & - & - & $12.3-18.21$ & 15.91 \\
\hline 3 & Taxi & Female & - & - & - & $4.80-8.34$ & 6.87 \\
\hline 4 & Taxi & Male & - & - & - & $5.66-9.03$ & 7.50 \\
\hline 5 & Bus & Female & Usual & Sitting & Uncrowded & $5.10-9.91$ & 7.95 \\
\hline 6 & Bus & Female & Usual & Sitting & Crowded & $6.02-14.09$ & 8.49 \\
\hline 7 & Bus & Female & No & Standing & Uncrowded & $5.31-13.21$ & 9.88 \\
\hline 8 & Bus & Female & No & Standing & Crowded & $4.93-15.47$ & 10.60 \\
\hline 10 & Rail transit & Female & Usual & Sitting & Uncrowded & $3.43-9.86$ & 7.24 \\
\hline 11 & Rail transit & Female & Usual & Sitting & Crowded & $5.23-9.91$ & 8.27 \\
\hline 12 & Rail transit & Female & No & Standing & Uncrowded & $5.89-13.13$ & 8.79 \\
\hline 13 & Bus & Male & Usual & Standing & Uncrowded & $6.69-13.07$ & 12.20 \\
\hline 14 & Bus & Male & Usual & Standing & Crowded & $6.60-15.84$ & 13.45 \\
\hline 15 & Bus & Male & No & Sitting & Uncrowded & $5.02-8.32$ & 7.80 \\
\hline 16 & Bus & Male & No & Sitting & Crowded & $5.14-8.99$ & 8.84 \\
\hline 17 & Rail transit & Male & Usual & Standing & Uncrowded & $7.40-23.07$ & 14.43 \\
\hline 19 & Rail transit & Male & Usual & Standing & Crowded & $6.60-31.31$ & 15.68 \\
\hline
\end{tabular}


Table 2 - Variance analysis results

\begin{tabular}{||l||c|c|c|c|c||}
\hline \hline Influence factor & Gender & Travel mode & Riding posture & Luggage level & Crowded level \\
\hline$F$ & 11.663 & 2.034 & 13.213 & 1.520 & 1.452 \\
\hline Significance & 0.001 & 0.156 & 0.000 & 0.219 & 0.230 \\
\hline
\end{tabular}

Table 3 - Physical energy expenditure per unit time

\begin{tabular}{||l|c|c|c|c||}
\hline \multirow{2}{*}{} & Walk $[\mathrm{KJ} / \mathrm{min}]$ & \multirow{2}{*}{ Car $[\mathrm{KJ} / \mathrm{min}]$} & \multicolumn{2}{|c||}{ Bus/Rail transit $[\mathrm{KJ} / \mathrm{min}]$} \\
\cline { 4 - 5 } & & & Sitting & Standing \\
\hline \hline Male & 15.59 & 7.49 & 9.69 & 13.94 \\
\hline Female & 13.10 & 6.36 & 7.99 & 9.97 \\
\hline
\end{tabular}

The influence degree of gender, travel mode, riding posture, luggage level and crowded level on the physical energy expenditure were determined by the variance analysis of experiment data. The results are shown in Table 2.

According to the value of $F$ and significance, it shows that the riding posture and gender have significant influence on TPEE; moreover, travel mode, luggage level and crowded level have no significant influence on TPEE. In order to solve this better, only these two factors were considered, riding posture and gender, and taking a bus and rail transit were taken into consideration together as public transportation. Then the mean value of travel physical energy expenditure per unit time was calculated as shown in Table 3.

\section{PHYSICAL ENERGY EXPENDITURE COEFFICIENT}

In this section, first, travel data were collected including travel time and travel money for different travel modes from two software programs, data by car from Dida-Ride-Sharing software, and data by public transportation from Baidu-Map software. Compared with the resident travel survey, this way can significantly reduce the workload and the cost of investigation. All data from these two software programs are corresponding. This means that for the same route, a piece of travel data by car, and also a piece of travel data by public transportation were obtained. Also, the physical energy expenditure is calculated for each piece of travel data according to the travel time and the physical energy expenditure obtained from Section 2. In this way, the formulation among travel time, money and physical energy expenditure can be established. By fitting all travel data, the value of physical energy expenditure coefficient will be determined.

\subsection{Travel data description}

Dida-Ride-Sharing is a ride-sharing mobile phone software, like Uber. A total of 1,200 pieces of actual travel data from Dida-Ride-Sharing were recorded. There are 300 pieces of data in every four directions, referring to the ride-sharing between the central urban area with the North, South, West, and East of the urban area. These data reflect the travel rule and the range of acceptable money of travelling by car. The average value of travel data by car is shown in Table 4.

By means of the route recommended function of Baidu-Map, the travel information by public transportation is obtained, including travel time, the minimum fare (it is assumed that travellers who have smart cards can enjoy regular $50 \%$ discount of the bus fare), the number of transfers, and the total distance of walking. In order to verify the reliability of data from Baidu-Map, 60 pieces of data from the above 1,200 pieces of Dida-Ride-Sharing data were randomly selected, and the actual travel time of the

Table 4 - Travel data by car

\begin{tabular}{||l|c|c||}
\hline \multicolumn{1}{|c|}{ Direction } & Money by car (RMB) & Time by car [min] \\
\hline \hline Beijing-Tibet highway & 36.89 & 40.67 \\
\hline Beijing-Kaifeng highway & 36.43 & 38.30 \\
\hline Lianshi Street & 39.35 & 34.48 \\
\hline East Changan Street. & 48.66 & 54.45 \\
\hline Average & 40.33 & 41.98 \\
\hline
\end{tabular}


Hong X, Meng L, An J. Quantifying Travel Physical Energy Expenditure for Urban Travellers - A Case Study of Beijing

Table 5 - Reliability analysis of the data from Baidu-Map

\begin{tabular}{||l|c|c|c||}
\hline & Data from Baidu-Map & Actual data & Deviation ratio \\
\hline \hline Average travel time by car [min] & 52.5 & 48.0 & $8.57 \%$ \\
\hline Average travel time by public transportation [min] & 60.0 & 57.5 & $4.17 \%$ \\
\hline $\begin{array}{l}\text { Average walk distance of travelling by public trans- } \\
\text { portation [km] }\end{array}$ & 1.160 & 1.235 & $6.47 \%$ \\
\hline
\end{tabular}

Table 6 - Travel data by public transportation

\begin{tabular}{||l|c|c|c||}
\hline \multicolumn{1}{|c|}{ Direction } & $\begin{array}{c}\text { Money by public transporta- } \\
\text { tion (RMB) }\end{array}$ & $\begin{array}{c}\text { Time by public transportation } \\
{[\mathrm{min}]}\end{array}$ & $\begin{array}{c}\text { Total distance of walking } \\
{[\mathrm{km}]}\end{array}$ \\
\hline \hline Beijing-Tibet highway & 4.56 & 76.46 & 1.267 \\
\hline Beijing-Kaifeng highway & 4.62 & 73.77 & 1.104 \\
\hline Lianshi Street & 4.57 & 82.27 & 1.127 \\
\hline East Changan Street & 5.81 & 90.36 & 1.342 \\
\hline Average & 4.89 & 80.72 & 1.210 \\
\hline
\end{tabular}

route for driving recommended by Baidu-Map with the same OD was recorded. The results are shown in Table 5.

Table 5 shows that the data from Baidu-Map are reliable. The deviation ratio with actual data is within an acceptable range. It can be also seen that Baidu-Map provides the travel time by public transportation including the processes of walking, waiting and travelling. Therefore, the travel information is obtained by the public transportation from Baidu-Map under the same OD obtained from Dida-Ride-Sharing software. The average value of travel data by public transportation is shown in Table 6.

\subsection{Quantifying the value of physical energy expenditure coefficient}

Research on the time coefficient is abundant enough. The value of time coefficient can be calculated with GDP per capita and annual working hours [10] as shown in Formula 1.

$$
\lambda=\frac{G D P}{D \cdot H}
$$

where $\lambda$ is the travel time coefficient (RMB/min); $G D P$ is the GDP per capita; $D$ is the annual working days; and $H$ is the number of working hours per day.

From the statistical data released by the State Statistics Bureau, it is known that in 2017 in Beijing, $G D P=21,330 \mathrm{RMB}, D=249$ days. According to 8 -hour working per day, the value of travel time coefficient can be calculated for residents in Beijing as follows.

$$
\lambda=\frac{21330}{249 \cdot 8 \cdot 60}=0.178
$$

In the process of travelling by car, it can be assumed that travellers do not need additional walk, and then physical energy expenditure is related to the physical energy expenditure per unit time and travel time. Then:

$E_{1}=T_{1} \cdot e_{1}$

where $T_{1}$ is the travel time, and $e_{1}$ is the physical energy expenditure per unit time by car.

In the process of travelling by public transportation, travellers need to walk between the origin/ destination with bus stations, which also involves the walk of transfer. Then:

$E_{2}=\left(T_{2}-\frac{l_{w}}{v_{w}}\right) \cdot e_{2}+\frac{l_{w}}{v_{w}} \cdot e_{w}$

where $e_{2}$ is the physical energy expenditure per unit time by public transportation, and the value is different between different genders and different riding postures; $l_{w}$ is the total walking distance of travelling by public transportation; $v_{w}$ is the average walking speed of travellers; $e_{w}$ is the physical energy expenditure per unit time by walking.

Travelling by car or public transportation features differences in money, travel time and travel physical energy expenditure. According to Formulae 3 and 4, TPEE is calculated for every piece of travel data from Dida-Ride-Sharing software and BaiduMap software. The linear correlation between money difference, travel time difference and physical energy expenditure difference by SPSS is analysed. The results show that there is a linear relationship between every two subjects among money difference, travel time difference and physical energy expenditure difference. So there is: 
$\beta\left(U_{2}-U_{1}\right)+\lambda\left(T_{2}-T_{1}\right)+\delta\left(E_{2}-E_{1}\right)-Z=0$

$\delta=\frac{\beta\left(U_{1}-U_{2}\right)+\lambda\left(T_{1}-T_{2}\right)+Z}{E_{2}-E_{1}}$

where $\delta$ is the travel physical energy expenditure coefficient. The value of $\delta$ refers to the additional money paid for reducing the unit travel physical energy expenditure, and the unit is $\mathrm{RMB} / \mathrm{KJ}$ or $\mathrm{RMB} /$ $\mathrm{Kcal} ; \beta$ is the money coefficient, $\beta=1 ; U_{1}$ and $U_{2}$ are the money by car and public transportation, respectively; $T_{1}$ and $T_{2}$ are the travel times by car and public transportation, respectively; $E_{1}$ and $E_{2}$ are the physical energy expenditures by car and public transportation, respectively.

According to Formulae 3, 4 and 6, physical energy expenditure coefficient can be calculated as follows:

$\delta=\frac{\left(U_{1}-U_{2}\right)+\lambda \cdot\left(T_{1}-T_{2}\right)+Z}{T_{2} \cdot e_{2}+\left(e_{w}-e_{2}\right) \cdot \frac{l_{w}}{v_{w}}-T_{1} \cdot e_{1}}$

where the values of $U_{1}, U_{2}$ and $T_{1}, T_{2}$ can be obtained from Dida-Ride-Sharing software and BaiduMap software; $\lambda=0.178 \mathrm{RMB} / \mathrm{min}$ according to Formula 2. According to Table $3, e_{1}$ is $7.49 \mathrm{KJ} / \mathrm{min}$ for males, and $6.36 \mathrm{KJ} / \mathrm{min}$ for females; $e_{2}$ is $13.94 \mathrm{KJ} /$ min for males standing, and $9.97 \mathrm{KJ} / \mathrm{min}$ for females standing; $e_{2}$ is $9.69 \mathrm{KJ} / \mathrm{min}$ for males sitting, and $7.99 \mathrm{KJ} / \mathrm{min}$ for females sitting; $e_{w}$ is $15.59 \mathrm{KJ} /$ min for males, and $13.1 \mathrm{KJ} / \mathrm{min}$ for females; $v_{w}$ is $80 \mathrm{~m} / \mathrm{min}$ [9].

Multivariate linear regression analysis of the experimental data by SPSS was conducted. The results show that the regression equation has a higher degree of fitting for the sample data points. The linear model can be determined as follows:

$U_{1}-U_{2}=0.178\left(T_{2}-T_{1}\right)+0.058\left(E_{2}-E_{1}\right)+3.357$

According to Formula 8 the value of travel physical energy expenditure coefficient $\delta$ is $0.058 \mathrm{RMB} / \mathrm{KJ}$.

\section{TRAVEL MODE CHOICE}

There are some studies on travel mode choice [11]. In this paper, the impact factors on travel mode choice like economic cost, time cost and physical energy expenditure cost are considered.

\subsection{Economic cost}

Economic cost is calculated by different pricing strategies for different transport modes. The operation enterprises of urban rail transit adopt the segmenting pricing strategy. Ticket fare relates to the distance between origin stations and destination stations. As for the operation enterprises of bus, they calculate the bus fare according to two ways, single ticket fare strategy and segmenting pricing strategy. The single ticket fare strategy can be considered as one special circumstance of the segmenting pricing strategy; that is to say, the fee standard for each segment is the same in the single ticket fare strategy. The fare can be calculated as follows:

$M_{i, j}^{s}=\left\{\begin{array}{c}C M_{0}^{s}, 0 \leq L_{i, j}^{s} \leq L_{0}^{s} \\ C M_{1}^{s}, L_{0}^{s} \leq L_{i, j}^{s} \leq L_{1}^{s} \quad \forall i, j \in N_{s} \\ \vdots \\ C M_{l}^{s}, L_{l-1}^{s} \leq L_{i, j}^{s} \leq L_{l}^{s}\end{array} \quad \forall\right.$

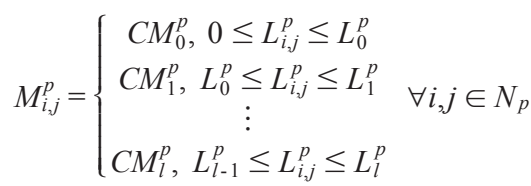

where $M_{i, j}^{s}, M_{i, j}^{p}$ and $L_{i, j}^{s}, L_{i, j}^{p}$ are the fare and distance from origin station $i$ to destination station $j$ by transit and bus, respectively; $C M_{l}^{s}$ and $C M_{l}^{p}$ are the fee standards of each segment for transit and bus, respectively; $L_{l}^{s}$ and $L_{l}^{p}$ are the distances of segment for fee standard changing of transit and bus, respectively.

Economic cost for travelling by taxi has non-linear correlation with travel distance. The operation enterprises of taxi charge the fixed fee within some range of travel distance, namely flag down fare, and the part beyond the range charged by the fee standard of per kilometre. Therefore, the fee for taxi can be calculated as follows:

$M_{i, j}^{t}=\left\{\begin{array}{l}C M_{0}^{t}+C M_{f}^{t}, 0 \leq L_{i, j}^{t} \leq L_{0}^{t} \\ C M_{0}^{t}+\mu^{t}\left(L_{i, j}^{t}-L_{0}^{t}\right)+C M_{f}^{t}, L_{i, j}^{t}>L_{0}^{t}\end{array} \quad \forall i, j \in N_{t}\right.$

where $M_{i, j}^{t}$ and $L_{i, j}^{t}$ are the fee and distance from origin station $i$ to destination station $j$, respectively; $C M_{0}^{t}$ is the flag down fare; $L_{0}^{t}$ is the travel distance charged within the flag down fare; $\mu^{t}$ is the fee standard of per kilometre, and $C M_{f}^{t}$ is the additional fee including fuel surcharges, toll and so on.

\subsection{Time cost}

Time cost refers to travel time. The travel time can be calculated by the travel distance and average speed as follows:

$$
\begin{aligned}
& T_{i, j}^{s}=\frac{L_{i, j}^{s}}{\bar{v}_{s}} \quad \forall i, j \in N_{s} \\
& T_{i, j}^{p}=\frac{L_{i, j}^{p}}{\bar{v}_{p}} \quad \forall i, j \in N_{p}
\end{aligned}
$$


$T_{i, j}^{w}=\frac{L_{i, j}^{w}}{\bar{v}_{w}} \quad \forall i, j \in N_{w}$

where $T_{i, j}^{s}, T_{i, j}^{p}, T_{i, j}^{w}$ are the travel time from origin station $i$ to destination station $j$ by urban rail transit, bus and walk, respectively; $\bar{v}_{s}, \bar{v}_{p}, \bar{v}_{w}$ are the average speed of trains, buses and walking, respectively.

The running speed of taxis is affected by the traffic flow. According to the function of the American Federal Highway Administration (BPR function), the travel time by taxi can be calculated as follows:

$T_{i, j}^{t}=T Z_{i, j}^{t} \cdot\left[1+\alpha\left(\frac{q}{C A}\right)^{\beta}\right]$

$T Z_{i, j}^{t}=\frac{L_{i, j}^{t}}{\bar{v}_{t}} \quad \forall i, j \in N_{t}$

where $T_{i, j}^{t}$ is the travel time by taxi from origin node $i$ to destination node $j$; $\bar{v}_{t}$ is the free-flow speed of taxi; $T Z_{i, j}^{t}$ is the travel time by taxi from origin node $i$ to destination node $j$ at the free-flow speed; $q$ is the traffic volume on the road at that time; $C A$ is the actual traffic capacity of the road; $\alpha$ and $\beta$ are the model parameters, generally speaking, $\alpha=0.15, \beta=4$ [8].

\subsection{Physical energy expenditure cost}

Physical energy expenditure cost for travellers is the product of physical energy expenditure per unit time and travel time. According to the above analysis, it is known that gender and riding posture have significant influence on the physical energy expenditure. Therefore, the travellers are classified as shown in Table 7. Then, the physical energy expenditure per unit time can be determined for each type of travellers by different travel modes according to Table 3.

The physical energy expenditure cost can be calculated as follows:

$$
\begin{array}{ll}
E_{i, j}^{s, m}=e_{s, m} T_{i, j}^{s} \quad \forall i, j \in N_{s} \\
E_{i, j}^{p, m}=e_{p, m} T_{i, j}^{p} \quad \forall i, j \in N_{p} \\
E_{i, j}^{t, m}=e_{t, m} T_{i, j}^{t} \quad \forall i, j \in N_{t} \\
E_{i, j}^{w, m}=e_{w, m} T_{i, j}^{w} \quad \forall i, j \in N_{w}
\end{array}
$$

where $E_{i, j}^{s, m}, E_{i, j}^{p, m}, E_{i, j}^{t, m}$ and $E_{i, j}^{w, m}$ are the physical energy expenditures from origin $i$ to destination $j$ for the $m$-th type of travellers by urban rail transit, bus, taxi and walk, respectively, and $e_{s, m}, e_{p, m}, e_{t, m}$ and $e_{w, m}$ are the physical energy expenditures per unit time for the $m$-th type of travellers by urban rail transit, bus, taxi and walk, respectively.

In this paper, the generalized cost function consists of economic cost, time cost and physical energy cost as shown in Formula 20.

$$
F=\omega_{m} M+\omega_{t} \lambda T+\omega_{e} \delta E
$$

where $F$ is the synthetically generalized cost; $\omega_{m}, \omega_{t}$ and $\omega_{e}$ are the weight coefficients of economic cost, time cost and physical energy cost, respectively.

\subsection{Travel mode choice model}

The utility theory considers that travellers always tend to select a travel mode to maximize the utility. The utility function includes two parts: the observable part and the random part. It is determined that the value of utility for the $m$-th type of travellers choosing mode $r$ is $U_{m}(r)$ as follows:

$U_{m}(r)=V_{m}(r)+\varepsilon_{m}(r) \quad \forall r \in R$

where $V_{m}(r)$ and $\varepsilon_{m}(r)$ are the observable part and the random part, respectively; $R$ is the set of effective transport modes. The observable part of utility function can be represented by the generalized cost of effective transport modes as follows:

$V_{m}(r)=-F_{m}(r)$

The random part of the utility function consists of personal perception differences, measurement error, different objects of reference, and so on. Multinomial logit model (MNL) hypothesizes that $\varepsilon_{m}(r)$ is independently distributed by the Gumbel variable. The probability for the $m$-th type of travellers choosing mode $r$ can be determined as follows:

$$
P_{m}(r)=\frac{\exp \left(\theta V_{m}(r)\right)}{\sum_{r \in R} \exp \left(\theta V_{m}(r)\right)}
$$

where $\theta$ is a non-negative constant, meaning the level of understanding of travellers to the generalized cost of different transport modes. The greater the value of $\theta$, the higher the level of travellers' understanding of the traffic network.

Table 7 -Classification of travellers

\begin{tabular}{|l||c|c|c|c||}
\hline \hline Classification & First type & Second type & Third type & Fourth type \\
\hline Gender & Male & Female & Male & Female \\
\hline Riding posture & Standing & Standing & Sitting & Sitting \\
\hline
\end{tabular}




\section{CASE STUDY}

This paper conducts the case study based on OD from Xizhimen to Tiantongyuan. Xizhimen is an important transportation hub in Beijing, connecting Metro Lines 2, 4 and 13. At the same time, there are many bus lines stopping at this station. In addition, a lot of commercial shops are located along the Xizhimen Street, which makes Xizhimen the regional centre of business with a large passenger flow. Tiantongyuan is located in the Changping district, the north of the Fifth Ring Road, which is a residential area. The density of dwelling population is high and the demand of travel is strong, resulting in typical commuting passenger flows. Metro Lines 5, 8 and 13 all pass through this area, and many bus lines can meet the traffic demand.

\subsection{Parameter setting}

The ticket fare for urban rail transit and bus in Beijing is shown in Tables 8 and 9, respectively.

In Beijing, the flag down fare for Taxi $C M_{0}^{t}$ is $13 \mathrm{RMB}$. The travel distance charged within the flag down fare $L_{0}^{t}$ is $3 \mathrm{~km}$. The fee standard of per kilometre $\mu^{t}$ is $2.3 \mathrm{RMB} / \mathrm{km}$, and the additional fee $C M_{f}^{t}$ is $1 \mathrm{RMB}$.
According to the data from the Beijing Comprehensive Traffic Survey [9], the average operating speed for urban rail transit $v_{s}$ is $35 \mathrm{~km} / \mathrm{h}$, the average operating speed for bus $v_{p}$ is $9.9 \mathrm{~km} / \mathrm{h}$, the average running speed for taxi $v_{t}$ is $20 \mathrm{~km} / \mathrm{h}$, and the average walking speed $v_{w}$ is $4.8 \mathrm{~km} / \mathrm{h}$.

It is hypothesized that the level of understanding of travellers of the generalized cost of different transport modes is the highest, and it is determined that the value of $\theta$ is 1 . Combined with the Beijing Forth Comprehensive Traffic Survey [9], the weight coefficients are determined as shown in Table 10.

\subsection{Results analysis}

The route recommended function of Baidu-Map is widely used by travellers. Before travelling, travellers are used to searching routes by Baidu-Map, and choosing one route according to their own preference. Therefore, six routes are determined from Xizhimen to Tiantongyuan from Baidu-Map software, as shown in Table 11. The symbols of $P, S$ and $T$ represent buses, urban rail transit, and taxi, respectively. Since there is a long distance between these two stations, walking is not considered as an option, so $R=\left\{P, S, T, P^{*} S, P^{*} P, S^{*} P, S^{*} S\right\}$, are determined.

Table 8 - Ticket fare for urban rail transit

\begin{tabular}{||l||c|c|c|c|c|c|c||}
\hline \hline Travel distance $[\mathrm{km}]$ & $0-6$ & $6-12$ & $12-22$ & $22-32$ & $32-52$ & $52-72$ & $72-92$ \\
\hline Ticket fare $[\mathrm{RMB} / \mathrm{per}$ person] & 3 & 4 & 5 & 6 & 7 & 8 & 9 \\
\hline
\end{tabular}

Table 9 - Ticket fare for bus

\begin{tabular}{||l||c|c|c|c|c|c|c||}
\hline \hline Travel distance $[\mathrm{km}]$ & $0-10$ & $10-15$ & $15-20$ & $20-25$ & $25-30$ & $30-35$ & $35-40$ \\
\hline Ticket fare $[\mathrm{RMB} /$ per person] & 2 & 3 & 4 & 5 & 6 & 7 & 8 \\
\hline
\end{tabular}

Table 10 - Weight coefficients of each factor for each type of traveller

\begin{tabular}{||l|c|c|c|c||}
\hline & First type & Second type & Third type & Fourth type \\
\hline \hline Weight coefficient of economic cost & 0.165 & 0.177 & 0.231 & 0.339 \\
\hline Weight coefficient of time cost & 0.692 & 0.655 & 0.492 & 0.264 \\
\hline Weight coefficient of physical energy cost & 0.077 & 0.180 & 0.331 & 0.397 \\
\hline
\end{tabular}

Table 11 - Routes from Xizhimen to Tiantongyuan

\begin{tabular}{||c|c|c|c||}
\hline Route number & Route & Lines (in order) & Transfer station \\
\hline \hline 1 & $\mathrm{~S} * \mathrm{~S}$ & Metro Line 2, Metro Line 5 & Lama Temple Station \\
\hline 2 & $\mathrm{~S}$ S & Metro Line 13, Metro Line 5 & Lishuiqiao Station \\
\hline 3 & $\mathrm{P} * \mathrm{~S}$ & Bus 44, Metro Line 5 & Lama Temple Station \\
\hline 4 & $\mathrm{~S} * \mathrm{P}$ & Metro Line 13, Bus 751 & Lishuiqiao Station \\
\hline 5 & $\mathrm{P}$ & Bus 620 & - \\
\hline 6 & $\mathrm{~T}$ & - & - \\
\hline
\end{tabular}


Hong X, Meng L, An J. Quantifying Travel Physical Energy Expenditure for Urban Travellers - A Case Study of Beijing

Table 12 - Generalized cost of each route for each type of traveller

\begin{tabular}{||c|c|c|c|c||}
\hline \hline Route number & First type & Second type & Third type & Fourth type \\
\hline \hline 1 & 8.85 & 10.60 & 13.71 & 12.45 \\
\hline 2 & 9.97 & 12.14 & 16.03 & 14.59 \\
\hline 3 & 10.31 & 12.32 & 15.95 & 14.41 \\
\hline 4 & 12.46 & 14.94 & 19.38 & 17.47 \\
\hline 5 & 10.25 & 12.78 & 17.42 & 28.08 \\
\hline 6 & - & - & 23.11 & \\
\hline
\end{tabular}

Table 13 - Probability of each route selected by each type of travellers

\begin{tabular}{||c|c|c|c|c||}
\hline Route number & First type & Second type & Third type & Fourth type \\
\hline \hline 1 & $54.60 \%$ & $65.78 \%$ & $81.09 \%$ & $75.70 \%$ \\
\hline 2 & $17.77 \%$ & $14.10 \%$ & $7.94 \%$ & $8.86 \%$ \\
\hline 3 & $12.64 \%$ & $11.76 \%$ & $8.68 \%$ & $10.71 \%$ \\
\hline 4 & $1.48 \%$ & $0.86 \%$ & $0.28 \%$ & $0.50 \%$ \\
\hline 5 & $13.47 \%$ & $7.46 \%$ & $2.00 \%$ & $4.23 \%$ \\
\hline 6 & - & - & $0.00 \%$ & $0.00 \%$ \\
\hline
\end{tabular}

Table 14 - Probability of each route selected only considering the economic cost and time cost

\begin{tabular}{|c|c|c|c|c||}
\hline Route number & First type & Second type & Third type & Fourth type \\
\hline \hline 1 & $32.28 \%$ & $31.36 \%$ & $27.39 \%$ & $21.61 \%$ \\
\hline 2 & $19.72 \%$ & $19.67 \%$ & $19.30 \%$ & $17.91 \%$ \\
\hline 3 & $11.55 \%$ & $11.62 \%$ & $11.78 \%$ & $11.08 \%$ \\
\hline 4 & $2.74 \%$ & $2.95 \%$ & $4.00 \%$ & $5.58 \%$ \\
\hline 5 & $33.70 \%$ & $34.40 \%$ & $37.53 \%$ & $43.81 \%$ \\
\hline 6 & - & - & $0.00 \%$ & $0.00 \%$ \\
\hline
\end{tabular}

Different generalized cost for different types of travellers choosing the same route is calculated, as shown in Table 12. According to the transport mode choice model in Table 11, the probability of each route selected by each type of traveller is calculated in Table 13. What is more, the probability of each route is calculated only considering the economic cost and time cost, and the results are shown in Table 14.

The results show that physical energy expenditure has influence on transport mode choice. When physical energy expenditure is taken into account, the probability of routes selected by travellers will agree more with the actual travel behaviour. Route 1 refers to taking urban rail transit through the whole process of travel, which will be more punctual and comfortable with a moderate fare.

\section{CONCLUSION}

It is determined that the value of physical energy expenditure coefficient $\delta$ is $0.058 \mathrm{RMB} / \mathrm{KJ}$, which means that travellers pay additional $0.058 \mathrm{RMB}$ to reduce $1 \mathrm{KJ}$ of travel physical energy expenditure.
The coefficient can provide references to determine the cost of unit $\mathrm{km}$ for taxi, the price of gasoline and the adjustment of fare for public transportation. The value of travel physical energy expenditure coefficient will be increased by enlarging the money difference between cars and public transportation, which will benefit from transferring the passenger flows from cars to the public transportation, and improve the share ratio of public transportation.

\section{ACKNOWLEDGEMENT}

This work has been financially supported by the National Natural Science Foundation of China (71571012, 71501014) and the research funding of China Railway Research and Development (Contract number: K2018X012).

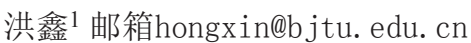

孟令云（通讯作者） ${ }^{1}$ 邮箱: lymeng@bjtu.edu.cn 安健 ${ }^{2}$ 邮箱: Marlin_tree@163.com

1 北京交通大学交通运输学院, 北京, 100044 , 中国

2 深圳市城市交通规划设计研究中心股份有限公司,

深圳，518026，中国 
城市交通出行者体能消耗定量研究: 以北京为例

摘要

出行者在出行过程中的体能消耗对出行方式选择 行为有一定的影响。然而, 关于出行体能消耗的定 量研究非常稀少。本文提出出行体能消耗系数的概 念, 以北京青年出行者为研究对象进行实验。综合 考虑出行者年龄、性别、交通方式、乘车姿势、负 重程度和车内的拥挤程度 5 个影响体能消耗的因素 设计实验场景, 分别得到通过步行、小汽车以及公 共交通出行的出行者单位时间体能消耗值。通过分 析实际出行费用、出行时间以及相应的体能消耗, 确定出行体能消耗系数的值为 0.058 元/千焦, 这意 味着出行者每支付 0.058 元, 就可以减少 1 千焦的体 能消耗。之后, 本文考虑出行费用、出行时间以及 体能消耗, 基于多项Logit模型建立出行者交通方式 选择模型。最后, 以北京西直门一一天通苑为实验 $O D$, 验证了当考虑不同类型出行者的出行体能消耗 时所得的交通方式选择结果, 更符合实际出行者出 行行为。

\section{关键词}

出行者体能消耗; 出行行为; 交通方式选择

\section{REFERENCES}

[1] Stradling S, Carreno M, Rye T, Noble A. Passenger perceptions and the ideal urban bus journey experience. Transport Policy. 2007;14(4): 283-292.

[2] Cox T, Houdmont J, Griffiths A. Rail passenger crowding, stress, health and safety in Britain. Transportation
Research Part A. 2006;40(3): 244-258.

[3] Hanying G. Study on Travelers' Behavior Based on the Physiology and Psychology in Urban Passenger Transportation. MSc thesis. Chengdu: Southwest Jiaotong University; 2007.

[4] Yang XG, An J, Liu HD, Teng J, Zhang D. Evaluation Architecture Discussion of Route-Level Transit Service Quality. Journal of Transportation Systems Engineering and Information Technology. 2010;10(4): 13-21.

[5] An J, Sun MZ, Guo JF. Analysis of Travel Energy Expenditure Based on Subjective Perception and Objective Measurement. Urban Transport of China. 2013;11(2): 73-82.

[6] Thorhauge M, Haustein S, Cherchi E. Accounting for the Theory of Planned Behaviour in departure time choice. Transportation Research Part F. 2016;38: 94-105.

[7] Hood VL, Granat MH, Maxwell DJ, Hasler JP. A new method of using heart rate to represent energy expenditure: the total heart beat index. Archives of Physical Medicine and Rehabilitation. 2002;83(9): 1266-1273.

[8] Wang SS, Huang W, Lu ZB. Deduction of link performance function and its regression analysis. Journal of Highway and Transportation Research and Development. 2006;23(4): 107-110.

[9] Beijing Municipul Committee of Communication. Beijing Forth Comprehensive Traffic Survey Report. Beijing's Traffic Development Research Centre, 2012.

[10] Zhao WT. Research on model of time value of commuter travel. MSc thesis. Beijing: Beijing Jiaotong University; 2013.

[11] Javanmardi M, Fasihozaman M, Shabanpour R, Mohammadian A. Mode choice modelling using personalized travel time and cost data. International Conference on Travel Behaviour Research; 2015. 